\title{
Control del pardeamiento enzimático en manzanas cortadas (Red delicious) mediante un sistema de envasado activo
}

\section{(Enzymatic browning control in cut apples (Red delicious) through a system of active packaging)}

\author{
Felipe Jadán Piedra ${ }^{1}$
}

\begin{abstract}
Resumen:
Entre los mecanismos de deterioro que tienen lugar en frutas y hortalizas frescas sometidas a un proceso de corte, destaca el pardeamiento enzimático, consecuencia de la actividad de la enzima polifenoloxidasa (PPO), sobre, los compuestos fenólicos que se liberan por rotura celular. En este trabajo se planteó la posibilidad de limitar la actividad de la enzima (PPO) presente en esta variedad de manzana mediante una tecnología de envasado activo, con materiales que incorporan agentes antioxidantes activos contra la polifenoloxidasa. Se desarrollaron películas del copolímero etileno-alcohol Vinílico (EVOH) con combinaciones de ácido ascórbico, y 4-hexilresorcinol. Dichas películas se utilizaron como recubrimiento de rodajas de manzana y se registró la evolución de color de las mismas y la actividad enzimática, así como la cinética de liberación de los agentes a medios simulantes de alimentos. En todos los casos, los resultados mostraron una mejora de estabilidad del color y reducción de la actividad enzimática de la manzana. La película con un $10 \%$ de agente antioxidante en la relación 3/1 de 4-hexilresorcinol/ácido ascórbico, fue la más eficiente.
\end{abstract}

Palabras clave: Polifenoloxidasa; 4-hexilresorcinol; ácido ascórbico.

\begin{abstract}
:
Enzymatic browning is one of the most relevant mechanisms of deterioration that take place in fresh-cut fruit and vegetables, as a consequence of the activity of the polyphenol oxidase enzyme on the phenolic compounds release after cellular lysis. This work is focused on the reduction of these enzymatic activity by an active packaging technology, which make use of a material that incorporates antioxidant active agents. Thus, films of ethylene-vynil alcohol copolymer (EVOH) containing a typical food antioxidant, such as ascorbic acid and a polyphenol oxidase-inhibiting agent, the 4-hexylresorcinol have been developed and used to wrap apple slices. The evolution of color, the enzymatic activity and the kinetic of agents release to food simulants were monitored. The results showed an improvement of apple slice color stability and a reduction of the enzymatic activity. The film with $10 \%$ of agents in $3 / 1$ ratio (4-hexylresorcinol/ascorbic acid) provided the best results.
\end{abstract}

Keywords: Polyphenoloxidase., 4-hexylresorcinol., ascorbic acid.

\footnotetext{
${ }^{1}$ Universidad Técnica de Manabí, Portoviejo - Ecuador, (fjadan@utm.edu.ec)
} 


\section{Introducción}

Las frutas y hortalizas son alimentos perecederos. Cuando no están sujetos a procesos de conservación, en muy poco tiempo presentan cambios físiológicos que acortan su vida útil, como consecuencia de la acción de microorganismos y de la actividad metabólica propia. Los productos vegetales frescos se deterioran rápidamente al cortarlos debido a los daños provocados sobre los tejidos, tales como el ennegrecimiento de las células al descomponerse la membrana celular, y los constituyentes del protoplasma (Lee, 2014). Los indicadores de deterioro más apreciables son los cambios de textura y de color, así como la contaminación microbiológica (Landim, APM, et al, 2016).

La alteración del color de la superficie cortada es un problema observado en diferentes productos vegetales entre estos: lechuga, repollo de col, melocotón, manzana (Bae, et al, 2015; Paillart, et al, 2016; Chukwan, et al, 2017; Cárdenas-Pérez et al, 2017). Estos cambios de color superficial se atribuyen a un proceso de pardeamiento enzimático por el cual los compuestos fenólicos son oxidados hasta formas quinónicas, mediante reacciones catalizadas por enzimas denominadas genéricamente polifenoloxidasas (PPO) (Quevedo et al, 2016).

Al ser la PPO de catalizar reacciones de oxidación de compuestos polifenólicos en presencia de oxígeno molecular, se debe tratar de controlar dicha oxidación para evitar la acción de estos precursores en las reacciones de pardeamiento que ocurren en los procesos de posrecolección y manipulación, por lo cual se ha estudiado la posibilidad de incorporar dos antioxidantes en diferentes concentraciones y combinaciones como agentes de control efectivo en la oxidación polifenólica.

Una alternativa a la incorporación directa de los antioxidantes sobre la fruta es la utilización de tecnologías de envasado activo con materiales con capacidad antioxidante. El Reglamento de la Comunidad Europea (CE) No 450/2009 (CE, 2009) define como materiales activos los diseñados para incorporar intencionadamente componentes que liberarán sustancias en el alimento envasado o en su entorno o absorberán sustancias del alimento o de su entorno con objeto de prolongar la vida útil o mejorar el estado del alimento envasado. Con esta idea, un material activo antioxidante incorpora aditivos antioxidantes en un material polimérico que permita su liberación controlada y progresiva para incorporarse al alimento envasado evitando su oxidación.

En este trabajo se propone un sistema de envasado activo antioxidante para el control del pardeamiento enzimático en manzanas cortadas utilizando el 4-Hexilresorcinol y el ácido ascórbico como agentes de conservación. 


\section{Materiales y métodos}

Fueron utilizadas manzanas de la variedad Red Delicious, adquiridas en un supermercado local. Se seleccionaron frutos con similar forma, tamaño y grado de madurez. Se almacenaron en una cámara de refrigeración a $4^{\circ} \mathrm{C}$ hasta su uso.

El copolímero etileno alcohol vinílico $(E V O H)$, que se utilizó tuvo una concentración del 29\% molar de etileno proporcionado en forma de granza por The Nippon Synthetic Chemical Company (Nippon Gohsei), Japón).

Antioxidantes: 4-Hexilresorcinol (Sigma, Barcelona) y Ácido Ascórbico (Panreac, Barcelona). Tampones fosfato sódico 0,2 M pH 7 y 6,5; catecol 0,1M (Sigma, Barcelona); Tritón X-100 al 0.5\% $(\mathrm{p} / \mathrm{v})$ (Roche, Barcelona); polivinilpirrilidona al 4\% (p/v) (Scharlau, Barcelona); 1-propanol (Panreac, Barcelona).

\subsection{Color}

El color de las rodajas de manzana se determinó con un colorímetro Kónica Minolta CM 3500d. La medida se realizó frente a un blanco estándar, sobre una máscara de medición de $8 \mathrm{~mm}$, obteniendo los resultados en el espacio CIE L*a*b* y utilizando como referencia observador $10^{\circ} \mathrm{e}$ iluminante D65. Las muestras se cortaron con un diámetro de $3 \mathrm{~mm}$, se midieron por triplicado realizando tres medidas en posiciones diferentes en cada muestra de manzana.

\subsection{Actividad enzimática}

La actividad enzimática de la polifenoloxidasa se evaluó por espectrofotómetría UV/Vis utilizando un equipo Agilent 845X (Barcelona, España), de acuerdo con la metodología expuesta por Espín et al (1995). Para ello, se preparó el extracto crudo, homogenizando $50 \mathrm{~g}$ de pulpa de manzana pelada con $100 \mathrm{~mL}$ de buffer fosfato sódico 0,2 M a pH=7 en un ultra-Turrax T-18 (IKA, Scaufen, Alemania). Se centrifugó el homogenizado a 18.000 × g a $4{ }^{\circ} \mathrm{C}$ durante 30 minutos en una centrifuga Solvall RC-5B (Alemania) y el sobrenadante se separó con un filtro Whatman №1 (Whatman, Gran Bretaña). El extracto enzimático se mantuvo congelado a $-80{ }^{\circ} \mathrm{C}$ hasta el momento de su análisis.

Para efectuar el análisis, se adicionaron $2,7 \mathrm{~mL}$ de catecol $0,1 \mathrm{M}$ a 0,3 $\mathrm{mL}$ del extracto anterior y se midió el cambio de absorbancia a $420 \mathrm{~nm}$ durante unos $5 \mathrm{~min}$, determinando la pendiente del tramo lineal. Los resultados se expresaron como unidades de actividad enzimática, que se define como el cambio de absorbancia a $420 \mathrm{~nm}$ por minuto y por gramo de tejido extraído.

\subsection{Preparación de las películas activas}

Con objeto de determinar las concentraciones más adecuadas de los dos agentes antioxidantes en estudio, se efectuaron experiencias recubriendo rodajas de manzana con películas de EVOH 
con concentraciones del 3, 5 y 10\% de los agentes en la relación 3/1,1/1 y 1/3 HR/AA, y se siguió la evolución del color de las manzanas durante 4 días almacenadas a $4{ }^{\circ} \mathrm{C}$.

Se prepararon películas de EVOH con incorporación de 4-hexilresorcinol (HR) y ácido ascórbico (AA) en las siguientes proporciones respecto al peso de polímero puro: 2,5\% RES / 7,5\% AA (denominada 1:3 10\%), 5\% HR / 5\% AA (denominada 1:1 10\%), 7,5\% HR / 2,5\% AA (denominada $3: 110 \%$ ) y $3,75 \%$ HR / 1,25\% AA (denominada $3: 15 \%$ ).

Para la preparación de las películas se partió de EVOH 29 en granza. En cada película fueron tomados $4 \mathrm{~g}$ de granza que se disolvieron en $26,6 \mathrm{~g}$ de una mezcla de propanol/agua 1:1 a reflujo con agitación constante; se enfrió la disolución hasta a unos $40{ }^{\circ} \mathrm{C}$, para luego adicionar los agentes HR y AA en las cantidades correspondientes a cada muestra. Tras una breve homogenización, se vertió la disolución sobre una placa de vidrio con una varilla de extensión de $100 \mu \mathrm{m}$ de paso y se secó la película formada en un túnel de aire caliente durante 15 minutos. Tras el enfriado, se separó y almacenó la película en un desecador, hasta su uso.

\subsection{Evaluación de la actividad de las películas}

Con objeto de evaluar el efecto de las películas activas desarrolladas para el control del pardeamiento enzimático, se prepararon rodajas de $3 \mathrm{~mm}$ de espesor, las cuales fueron recubiertas en ambas caras con las películas a evaluar. Se prepararon cuatro muestras con cada

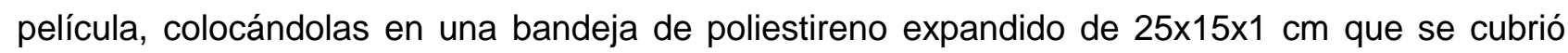
con película de PVC estirable para limitar la deshidratación de la manzana durante la experiencia. Las bandejas se almacenaron durante 4 días en refrigeración a $4{ }^{\circ} \mathrm{C}$ efectuando controles analíticos diarios de color y actividad enzimática.

\subsection{Liberación de los antioxidantes de las películas}

La cinética de liberación de los antioxidantes, desde las diferentes películas desarrolladas, se evaluó mediante ensayos de liberación a partir de las películas en contacto con varios medios utilizados habitualmente como simulantes de alimentos: etanol al $95 \%$, etanol al $10 \%$ y ácido acético al 3\%. Para efectuar las experiencias se sumergieron muestras de films de $6 \mathrm{~cm} 2$ (relación $6 \mathrm{dm} 2 / \mathrm{L}$ de acuerdo con la legislación vigente en la Unión Europea) en $10 \mathrm{~mL}$ de cada simulante en tubos Sovirel de $20 \mathrm{~mL}$ cerrados y envueltos en papel aluminio para evitar la degradación de los agentes activos por la acción de la luz. A las 2, 4, 6, 10, y 24 h se extrajeron muestras de cada película y simulante, midiendo la concentración de 4-hexilresorcinol y ácido ascórbico por espectroscopia UV-Vis a 280 y 250 nm, respectivamente (condiciones obtenidas mediante experiencias previas).

\section{Resultados y discusión}

Para el desarrollo de las películas activas se seleccionaron inicialmente los materiales copolímero 
de etileno alcohol vinílico $(E V O H)$ y polialcohol vinílico $(\mathrm{PVOH})$, polímeros solubles en agua o mezclas hidroalcohólicas de fácil extensión y secado y compatibles con los agentes antioxidantes a ensayar, 4-hexilresorcinol (HR) y ácido ascórbico (AA). Mediante experiencias previas, se descartaron las películas de $\mathrm{PVOH}$ por perder su integridad al contacto con la manzana. Así mismo, se estudió si existía algún efecto sinérgico entre $H R$ y $A A$, concluyendo que la incorporación conjunta en películas de EVOH con ambos antioxidantes protegió mejor las rodajas de manzana, como puede verse en la Figura 1, donde se evidencia que las muestras con 4hexilresorcinol + ácido ascórbico presentaban una apariencia general mejor a las $5 \mathrm{~h}$ de su preparación. En todas las muestras se observó que el tejido superficial de la manzana cambió de color, pasando a una tonalidad marrón, lo que correspondió a los aumentos en los valores de $a^{*}$ y $\mathrm{b}^{*}$ (Figura 2). De acuerdo con estos resultados, las mejores mezclas fueron las tres que contenían un $10 \%$ de antioxidantes y la que tenía un $5 \%$ en la relación $3: 1$ HR/AA.

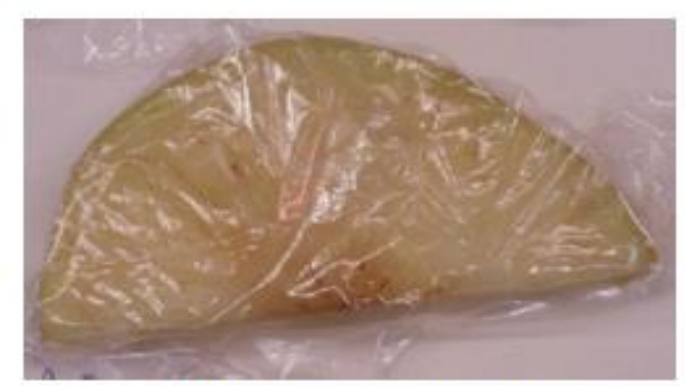

$\mathrm{EVOH}+$ Resorcinol

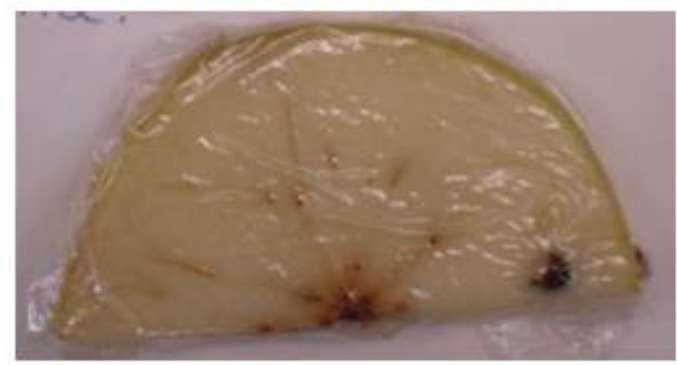

$\mathrm{EVOH}+$ Ac. Ascórbico + Resorcinol

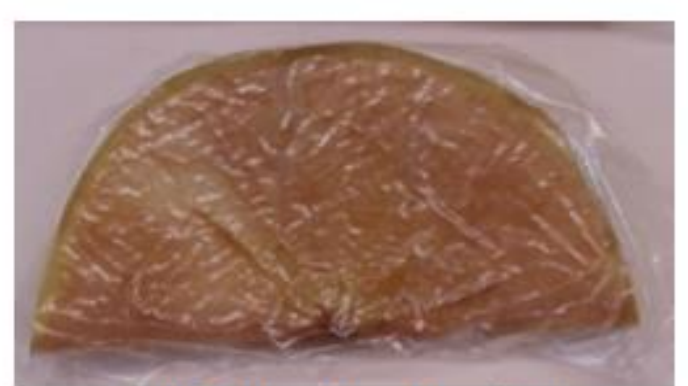

$\mathrm{EVOH}+$ Ac. Ascórbico.

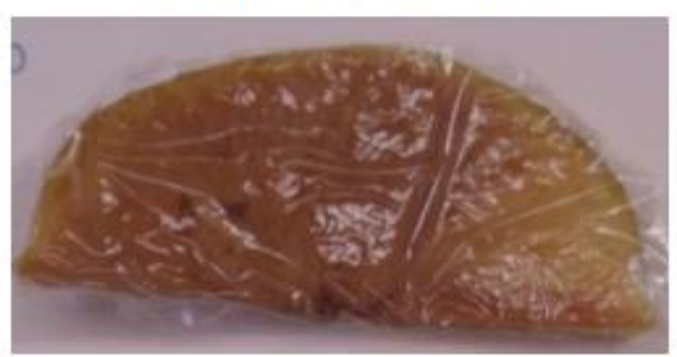

EVOH (blanco)

Figura 1. Efecto de los diferentes tratamientos aplicando ácido ascórbico y 4 hexilresorcinol en combinación a las $5 \mathrm{~h}$.

En consecuencia, se prepararon por "casting" cuatro películas de EVOH con las siguientes concentraciones de antioxidantes HR/AA, 1:3 10\%, 1:1 10\%, 3:1 10\% y 3:1 5\%, así como películas sin adición de antioxidantes como control. Con estas películas se envasaron rodajas de manzana, determinando los cambios de color de las rodajas de manzana, la actividad de la PPO presente en las mismas y la liberación de los agentes antioxidantes desde las películas durante 4 días en almacenamiento a $4{ }^{\circ} \mathrm{C}$.

\subsection{Color}

En la Figura 2 se muestra la evolución de los tres parámetros de color del espacio CIE lab medidos en la superficie de las rodajas de manzana para cada tratamiento. Como puede verse 
por la evolución de la coordenada $L^{*}$, las muestras redujeron ligeramente su luminosidad con el tiempo de almacenamiento, no obstante, las muestras envasadas con las películas activas presentaron un menor descenso de $L^{*}$ que la muestra sin recubrimiento (aire-control), si bien las diferencias entre tratamientos solo fueron significativas $(p<0,05)$ tras 4 días de almacenamiento y únicamente para la muestra $3: 1$ al $5 \%$.

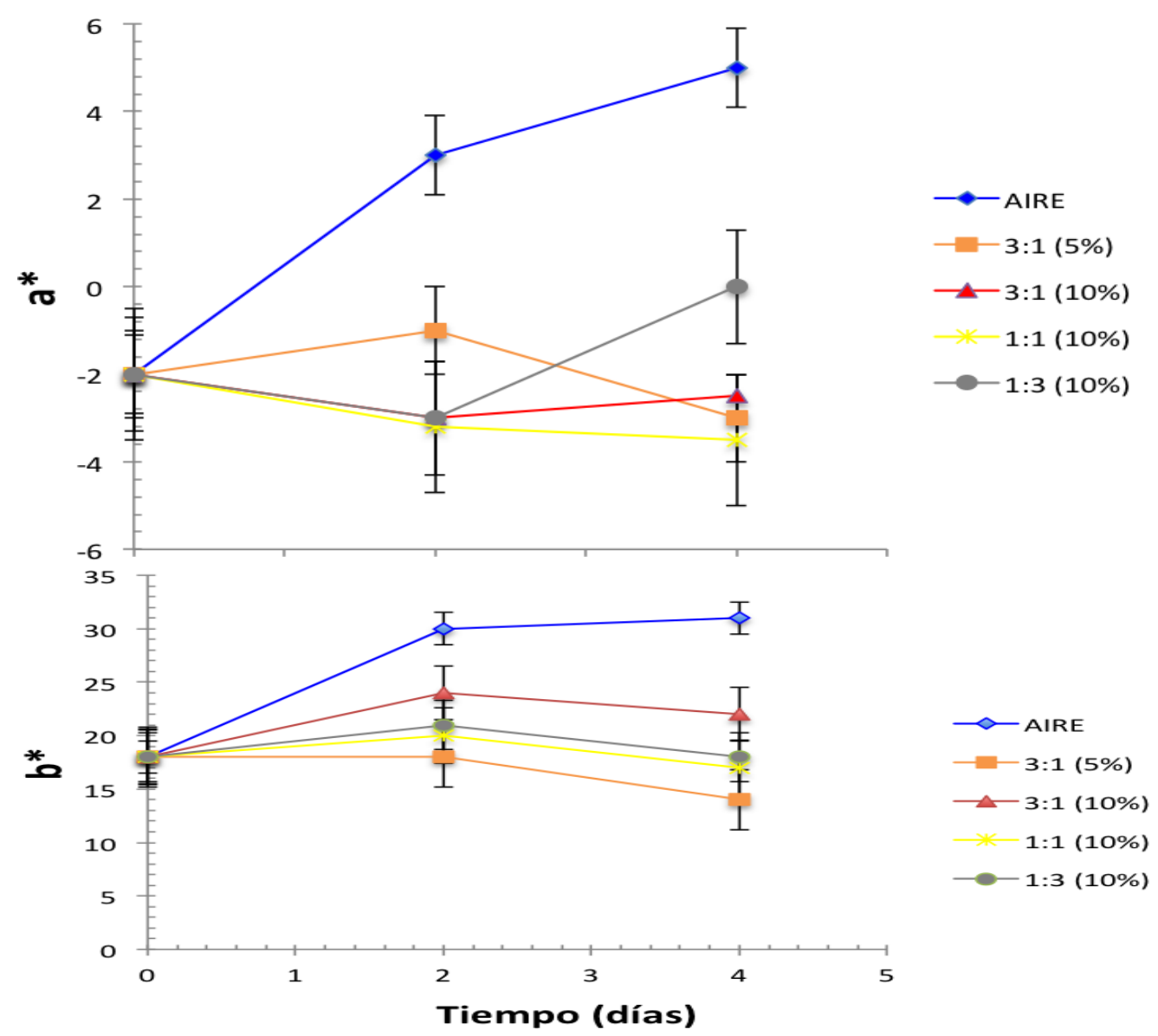

Figura 2. Evolución de los parámetros de color $L^{*}, a^{*} y b^{*}$, en rodajas de manzana sin tratamiento (aire-control), con separadores de $\mathrm{EVOH}$, empleando los antioxidantes 4hexilresorcinol, y ácido ascórbico almacenados en bandejas a $4{ }^{\circ} \mathrm{C}$.

En cuanto a la coordenada $\mathbf{a}^{*}$, se observó que la muestra control presentó un aumento continuado del valor de esta coordenada desde -2 hasta 5 , indicativo de tonalidades rojas (Figura 2). En cambio, las películas activas consiguieron mantener un valor constante de $a^{*}$ durante los 4 días de almacenamiento, significativamente diferente $(p<0.05)$ durante todo el almacenamiento respecto a la muestra sin tratamiento.

En cuanto a la coordenada $\mathbf{b}^{\star}$, las manzanas presentaron inicialmente un tono amarillo, que aumentó de forma notable en la muestra envasada al aire (Figura 2). Respecto a las muestras con películas activas, el valor de esta coordenada permaneció más estable durante el almacenamiento, significativamente menor que la muestra control, aunque sin diferencias entre los tratamientos. 


\subsection{Actividad enzimática de la Polifenoloxidasa}

El proceso mediante el cual se llega a producir la reacción de pardeamiento empieza con el corte en la superficie del tejido, momento en que se desestructura la célula y se produce la liberación de los componentes. La compartimentación celular es interrumpida produciéndose la mezcla de sustratos y enzimas, iniciándose las reacciones que dan lugar a compuestos activos que de otra manera no tendrían lugar. El pardeamiento enzimático puede ser controlado a través de métodos físicos y químicos, a menudo empleados en combinación. La tecnología más ampliamente utilizada en la práctica es el envasado en atmósferas modificadas (Min et al, 2017). Pero también se han propuesto tratamientos térmicos mínimos o no térmicos alternativos como son las altas presiones hidrostáticas (Linlin, et al, 2016).

Musetti et al., 2015 ha estudiado el control del pardeamiento enzimático de manzanas Red Delicious con 4-hexilresorcinol y metil jasmonato; utilizó ciclodextrinas como medio de inclusión, así como la combinación de tratamientos con el ácido alfa lipoico junto con el hexanal y el ácido ascórbico obteniéndose un control sobre la respiración celular y en consecuencia sobre el pardeamiento enzimático. La modificación de la atmósfera en el envase y un pretratamiento con antioxidantes también ha sido propuesto por Cortellino, G., Gobbi, S., Bianchi, G., Rizzolo, A., 2015 para alargar el tiempo de vida media en cortes de manzanas frescas, observándose efectos positivos en las características sensoriales de la fruta.

La determinación de la actividad enzimática se realizó con el propósito de verificar la efectividad de los tratamientos en la inhibición de la actividad de la enzima; ya que a menor actividad polifenólica mayor efectividad del tratamiento y, por tanto, mayor vida útil del producto.

Este análisis se realizó a los 0,2 y 4 días de almacenamiento a $4{ }^{\circ} \mathrm{C}$ en rodajas de manzana; las mismas mantuvieron el contacto por ambas caras con las diferentes películas ensayadas.

La Figura 3 recoge el efecto de los tratamientos y el tiempo de almacenamiento en la actividad de la polifenoloxidasa, expresada como variación de absorbancia a $420 \mathrm{~nm}$ por min y gramo de tejido. En la muestra control mantenida en aire-control, puede observarse que los valores de actividad enzimática se mantuvieron prácticamente constantes durante el período de almacenamiento ensayado. Para los tratamientos con antioxidantes, en todos los casos se observó una gran reducción de actividad a los 2 días de almacenamiento $(p<0,05)$, aumentando ligeramente a los 4 días de exposición. Los mejores resultados se obtuvieron con los materiales $1: 1$ al $10 \%$, y $3: 1$ al $10 \%$, que son aquellos que contenían las concentraciones mayores de 4hexilresorcinol, con actividades enzimáticas significativamente inferiores a las del resto. Por el contrario, la muestra $1: 310 \%$, presentó un aumento de actividad polifenoloxidasa a los 4 días sobre el control $(p<0.05)$. Quizás, en esta muestra hay un exceso de ácido ascórbico, que entonces podría presentar actividad prooxidadante, según lo informado por otros autores (Pshenichnyuk et al, 2016). 
Para determinar si las cantidades de 4-hexilresorcinol y ácido ascórbico incorporadas en las películas eran suficientes para desarrollar una actividad inhibidora de la acción enzimática de la polifenoloxidasa, se calcularon las cantidades presentes en una película de EVOH de superficie similar a la de contacto con la rodaja de manzana, y se adicionaron dichas cantidades directamente en el buffer fosfato sódico $(0,2 \mathrm{M}$ de $\mathrm{pH} 7)$, simulando una liberación total e inmediata de los agentes hacia el alimento. La Tabla 1 resume los resultados obtenidos para cada muestra, y la correspondiente a una muestra sin agentes (aire-control); como puede observarse, la PPO resultó completamente inhibida para todas las muestras que contienen los agentes en estudio.

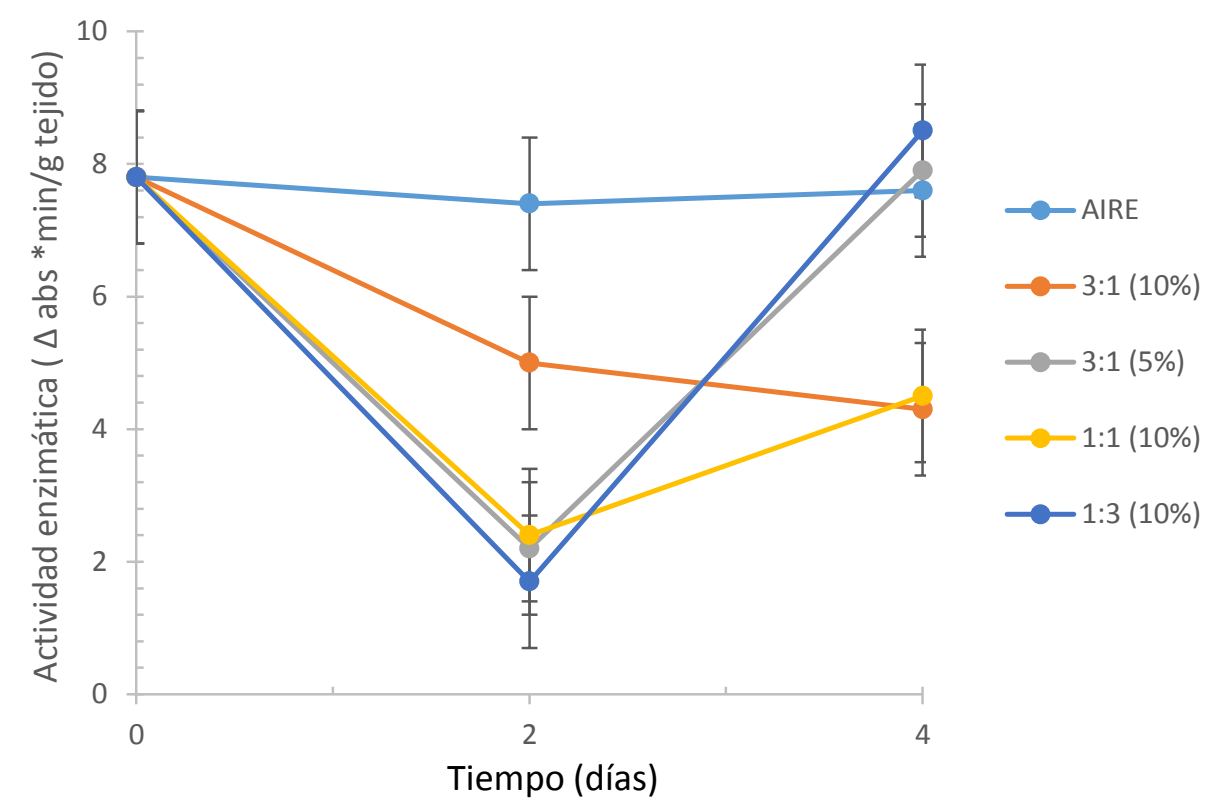

Figura 3. Efecto de los diferentes tratamientos y del tiempo de almacenamiento en la actividad de la polifenoloxidasa.

Tabla 1. Estimación de la actividad inhibidora de la actividad polifenoloxidasa en manzana (como variación de absorbancia a $420 \mathrm{~nm}$ por min y gramo de tejido) de los antioxidantes si se diera su liberación total e instantánea en el medio de extracción.

\begin{tabular}{lrrrrc} 
Muestra & Aire - control & $1: 310 \%$ & $1: 110 \%$ & $3: 15 \%$ & $3: 110 \%$ \\
\hline Actividad PPO & $6,67 \pm 0,19$ & $0,01 \pm 0,06$ & $0,011 \pm 0,1$ & $0,037 \pm 0,05$ & $0,008 \pm 0,02$
\end{tabular}

La diferencia observada entre este último ensayo y la exposición de la manzana a las películas de EVOH desarrolladas puede explicarse por dos causas, una liberación parcial y lenta de los agentes hacia la manzana o una difusión lenta de los agentes en el interior de la rodaja de manzana, o bien una combinación de ambas. El efecto matriz y la interacción de la misma con los agentes es en, principio, descartable ya que en ambos casos se incluye la manzana en el ensayo.

\subsection{Liberación de los agentes antioxidantes}

Se estudió la cinética de liberación de los agentes desde las diferentes películas desarrolladas mediante ensayos de liberación. Los resultados obtenidos, a partir de las películas en contacto 
con varios medios utilizados habitualmente como simulantes de alimentos se indican a continuación: En la Figura 4 se observan los resultados correspondientes a la liberación de ácido ascórbico en ácido acético al 3\%, medio simulante de alimentos ácidos.

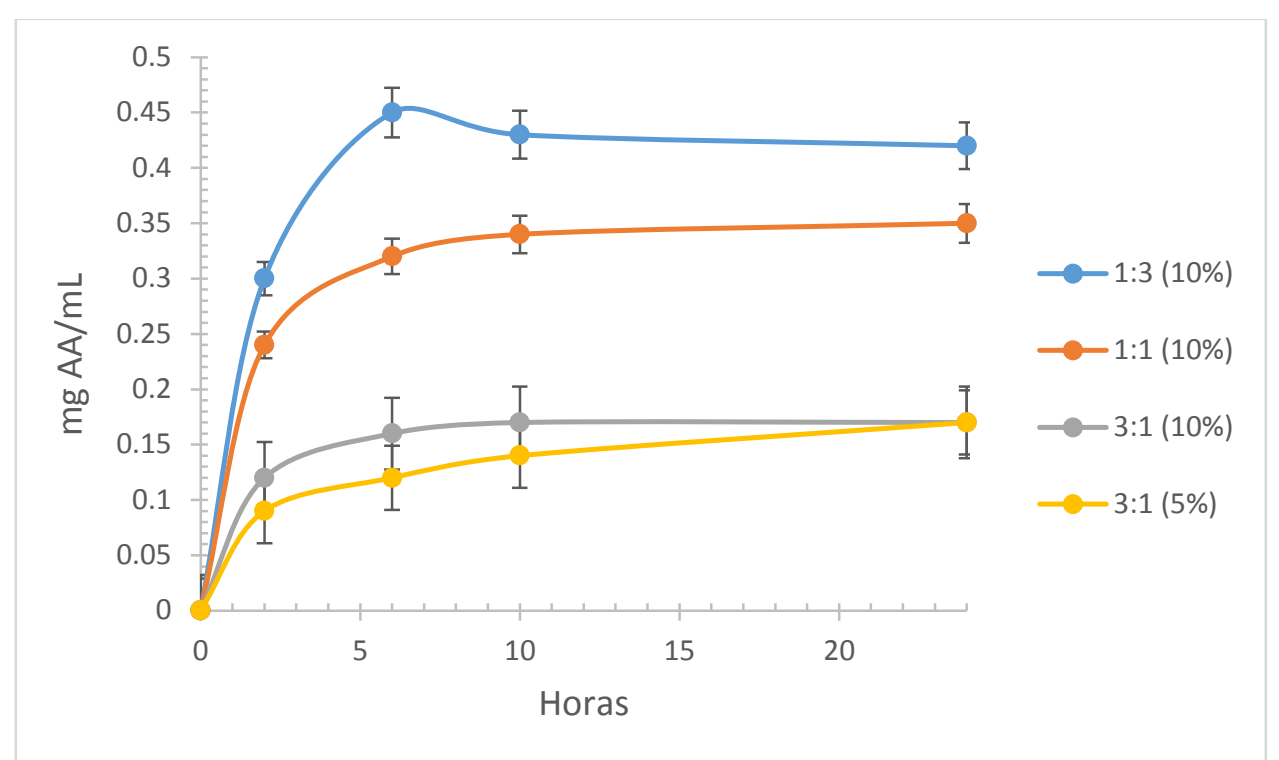

Figura 4. Liberación del ácido ascórbico en las diferentes películas activas, utilizando como medio simulante ácido acético al $3 \%$. Cada punto corresponde a la media obtenida de tres repeticiones.

Como puede verse, con todos los materiales se observa el mismo perfil de liberación, que corresponde al de una función exponencial que crece hasta un máximo. El mismo resultado se obtuvo para el resto de simulantes. En todos los casos parece alcanzarse el valor máximo de migración después de las 6 h de exposición.

La Figura 5 recoge los valores medidos experimentalmente para la liberación de 4-hexilresorcinol en el mismo simulante. Como puede verse en la figura (al igual que en el resto de simulantes), la liberación de 4-hexilresorcinol, sigue el mismo perfil que la de ácido ascórbico, si bien parece ser ligeramente más lenta, alcanzándose el estado estacionario a las $10 \mathrm{~h}$ de ensayo. 


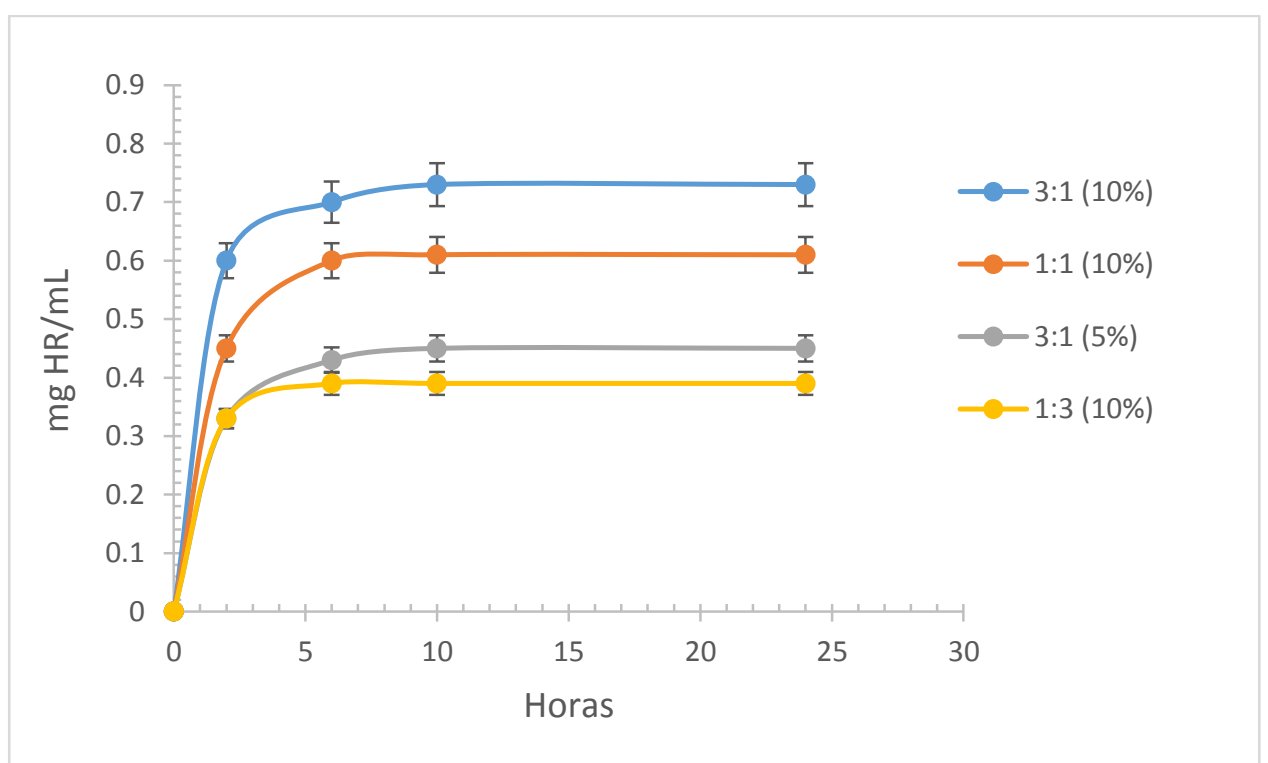

Figura 5. Liberación del 4- hexilresorcinol en las diferentes películas activas, utilizando como medio simulante ácido acético al 3\%. Cada punto corresponde a la media obtenida de tres repeticiones.

Asimismo, se evaluó la proporción de los agentes que se libera en cada simulante. Las figuras 6 y 7 muestran los resultados obtenidos para el ácido ascórbico y el 4-hexilresorcinol, respectivamente.

Como puede observarse en la Figura 6, el porcentaje de ácido ascórbico liberado del originalmente contenido en las diferentes películas varía alrededor del $40 \%$, con la excepción de las películas 3:1 al 5\% en ácido acético para la que se supera el $90 \%$ de liberación. Respecto al 4hexilresorcinol, la liberación alcanza prácticamente la extracción para las películas con menor contenido en este agente. Para las películas $3: 1$ al 10 y $5 \%$, la liberación es menor, especialmente en ácido acético y alcohol 10\%, donde probablemente el 4-hexilresorcinol sea menos soluble.

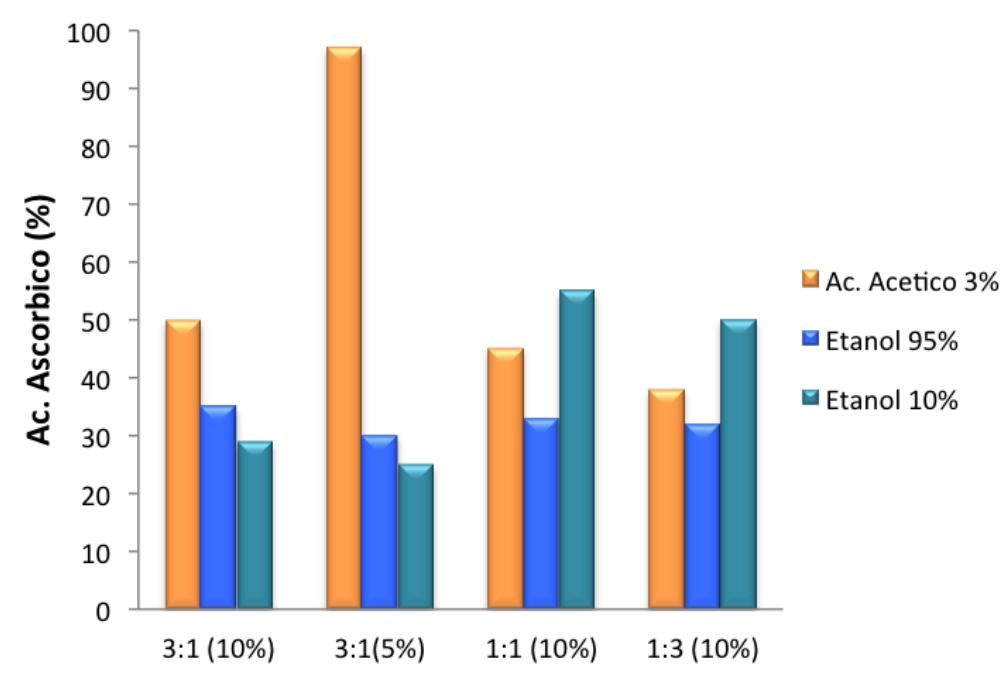

Figura 6. Porcentaje de ácido ascórbico liberado en los distintos simulantes respecto al contenido de las películas desarrolladas. 


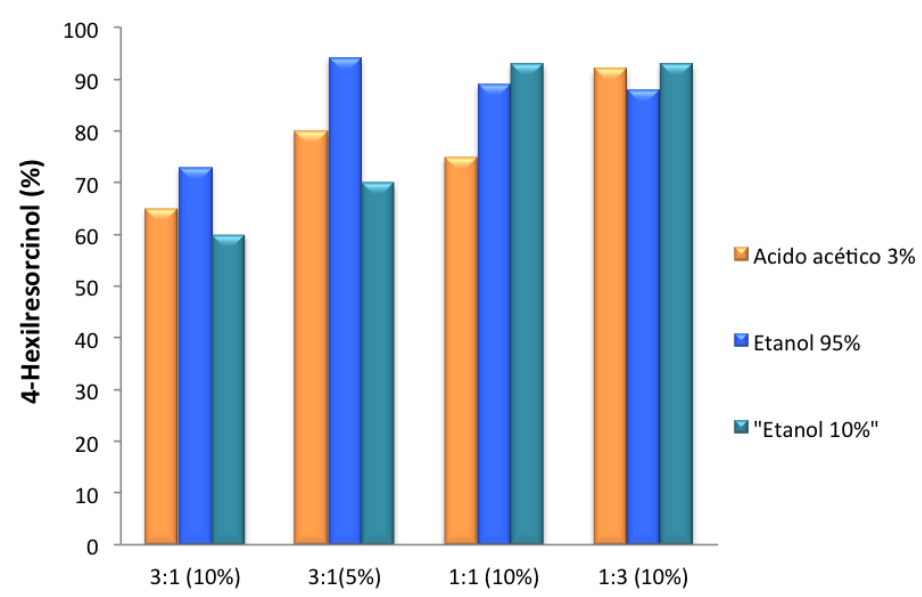

Figura 7. Porcentaje de 4-hexilresorcinol liberado en los distintos simulantes respecto al contenido en las películas desarrolladas.

\section{CONCLUSIONES Y RECOMENDACIONES}

Los resultados mostraron que la película con un 10\% de agentes antioxidantes en la relación 3/1 de 4hexil-resorcinol/ácido ascórbico fue la que presentó los mejores resultados.

El estudio de la cinética de liberación de los agentes a medios simulantes de alimentos acuosos, alimentos ácidos y alimentos grasos reveló que la liberación de ácido ascórbico es mayor en simulantes ácidos, mientras que no se observan diferencias en la liberación de 4-hexilresorcinol en los diferentes medios simulantes ensayados.

En todos los casos se observa una mejora de estabilidad en el color de la manzana y una reducción de la actividad polifenoloxidasa, sin embargo, se debería tratar de disminuir aún más la concentración de los diferentes antioxidantes, incorporando otros, cuyo origen no es la síntesis química tales como los flavonoides.

\section{Bibliografía}

Bae, SJ.,Eum, HL., Kim, BS.,Yoon, J., Hong, SJ. (2015). Comparison of the Quality of HighlandGrown Kimchi Cabbage Chong Gwang during Cold Storage after Pretreatments. Korean Journal of Horticultural Science \& Technology, 33(2), 233-241.

Cárdenas-Pérez, S., Méndez Méndez, J.V., Chanona-Pérez, J.J., Zdunek, A., Guemes-Vera, N., Calderón-Domínguez, G., Rodríguez González, F. (2017). Prediction of the nanomechanical properties of apple tissue during its ripening process from its firmness, color and microstructural parameters. Innovative Food Science and Emerging Technologies, 39, 79-87

Cortellino, G., Gobbi, S., Bianchi, G., Rizzolo, A. (2015). Modified atmosphere packaging for shelf life extensión of fresh-cut apples. Trends in Food Science \& Technology, 46(2), 320-330. 
Chukwan, T., Gary M, S., Judy, J., Diane M, B. (2017). The effect of high pressure processing on clingstone and freestone peach cell integrity and enzymatic browning reactions. Innovative Food Science and Emerging Technologies, 39, 230-240.

Landim, APM.,Barbosa, MINJ., Barbosa, JL. (2016). Influence of osmotic dehydration on bioactive compounds, antioxidant capacity, color and texture of fruits and vegetables: a review, 46(10), 1714-1722

Lee, EJ. (2014). Major Metabolites Involved in Skin Blackening of Niitaka Pear Stored under Cold Temperature. Korean Journal of Horticultural Science and Technology, 32(3), 359-365.

Linlin, L., Min, Z., Benu, A., Zhongxue, G. (2016). Recent advances in pressure modification-based preservation technologies applied to fresh fruits and vegetables. Food Reviews International, 33(5), 538-559.

Min, T., Xie, J., Zheng, ML., Yi, Y., Hou, WF., Wang, LM., Ai, YW., Wang, HX. (2017). The effect of different temperatures on browning incidence and phenol compound metabolism in fresh-cut lotus (Nelumbo nucifera G.) root. Postharvest Biology and Technology, 123, 69-76.

Musetti, A., Tagliazucchi, D., Montevecchi, G., Verzelloni, E., Antonelli, A., \& Fava, P. (2015). Characterization of a combined treatment with alpha-Lipoic acid for the control of enzymatic browning in fresh-cut golden delicious apples. Journal of Food Processing and Preservation, 39(6), 681-687.

Pshenichnyuk, SA.,Modelli, A., Lazneva,EF.,Komolov,AS. (2016). Hypothesis for the Mechanism of Ascorbic Acid Activity in Living Cells Related to Its Electron-Accepting Properties. Journal of Physical Chemistry A, 120(17),2667-2676.

Quevedo, R., Diaz, O., Valencia, E., Pedreschi, F., Bastias, JM., Siche, R. (2016). Differences Between the Order Model and the Weibull Model in the Modeling of the Enzymatic Browning. Food and Bioprocess Technology, 9(11), 1961-1967.

Paillart, MJM., Van der Vossen, JMBM., Lommen, E., Levin, E., Otma, EC., Snels, JCMA., Woltering, EJ. (2016). Organic acids produced by lactic acid bacteria (Leuconostoc sp.) contribute to sensorial quality loss in modified-atmosphere-packed fresh- cut iceberg lettuce. Acta Horticulturae, 1141, 289-296. 